\title{
Application of Phoenix Pattern in Chu Culture in Packaging Design
}

\author{
Wang Lijuan \\ Wuhan Business University, School of Arts, Hubei Wuhan China 430056
}

Keywords: phoenix pattern; packaging design; application

\begin{abstract}
Phoenix pattern is one of the representatives of Chinese traditional patterns. Its beautiful symbolic meaning and wonderful artistic expression are deeply loved by people. In particular, the phoenix pattern in Chu culture is influenced by the splendid and colorful regional culture of Chu State, which makes it unique. This paper takes the phoenix pattern in Chu culture as the research object. On the basis of collecting, sorting out and summarizing the relevant documents of Phoenix pattern in Chu culture, the application of Phoenix pattern decoration characteristics in packaging design was studied and analyzed.
\end{abstract}

Chuffed decoration is one of the quintessences of Chugging culture. It has a very important position, represents the unique national characteristics, permeates all aspects of people's lives, and is also rooted in people's ideas. Discussing phoenix pattern art in Chu culture, combining with modern packaging design, taking its essence to remove its dregs, is not only for the protection of intangible cultural heritage, but also for the development of modern packaging design. The innovative decoration not only greatly improves the popularity of products, but also meets the psychological needs of consumers in pursuit of art, reflects the eternal charm of Chugging history and culture, and also makes Chinese packaging design find its own accurate position in the domestic and international markets, so as to gain the competitive advantage of similar products.

\section{Overview of CH Fencing}

\subsection{Evolution of CH Phoenix Decoration in Chugging Culture}

Chinese decoration has a long history and brilliant achievements. As early as the Neolithic Age thousands of years ago, ancestors decorated their lives with symbolic totems of dragons and phoenixes on painted pottery. As the earliest geometric pattern decoration, primitive dragon and Phoenix totems were engraved on the front page of the history of Arts and crafts. As a splendid and colorful Southern culture with unique style, Chu culture has made brilliant achievements as early as the "Warring States Xiongnu" era, and phoenix pattern is the essence of the development of Chu culture. Chu people love Phoenix because Phoenix is the symbol of truth, goodness, beauty, dignity and serenity.

As a representative of regional culture, Chuffed decoration has now become the embodiment of auspiciousness and beauty in the hearts of Chinese people, with good wishes in their hearts. The Romantic color represented by Chuffed decoration is the best way to explore the spirit of pursuit 
and the broad momentum. In the past, it was mostly used in palace and folk arts and crafts. Now, through the rich imagination and artistic creativity of past generations of skilled craftsmen, Chuffing artistic charm and national form are displayed and become one of the cultural symbols and artistic symbols of the Chinese nation. Therefore, in modern packaging design, it is very important to better inherit Chuffed decoration.

\subsection{The Image of $\mathrm{CH}$ Fencing}

Lacquer art has a long history in China. In 1978, a large number of wooden lacquer were excavated at the Hemmed site in Yaounde County, which extended the lacquer art to the Neolithic Age. According to the archaeological data of the past 30 years, the lacquer excavated in the Chu tomb is the most complete and the largest number. For example, in 1957, more than 300 pieces of wooden lacquer were found in Chu Tomb No. 1 in Bunyan, Hen an Province. This is the largest discovery of lacquer in China. This time, the lacquer unearthed from Ch Tomb is exquisite and has a high artistic level. Up to now, the largest number of ancient lacquer objects in China is Hangzhou Museum in Huber Province. More than 6000 pieces of lacquer have been collected. The unearthed Chu lacquer is not only a large number, but also of a wide variety and, more importantly, of high artistic attainments. From the archaeological documents, the Chu people had mastered red, yellow, brown, blue, green, white and other colors. The more common colors were black, and the decorative patterns of Chu lacquer were smooth and beautiful. The most common pattern decoration in Chu lacquer is Phoenix pattern, and its manifestation is very rich and diverse. Whether it is the unique lacquer wood drum of Chu State, such as tiger sitting on Phoenix drum, or the daily necessities such as lacquer cup, lacquer plate, lacquer several, etc., whether it is the large lacquer coffin of Ming ware, or the small and lovely lacquer beans, the image of Phoenix bird pattern can be seen everywhere and varies from place to place. Chu lacquer about all aspects of Chu people's life, "life and death are inseparable from lacquer" is no exaggeration for Chu people. As shown in the table below:

Table 1. Location Characteristics of Phoenix

\begin{tabular}{|l|l|}
\hline Phoenix bird location & Formal characteristics \\
\hline Crested & $\begin{array}{l}\text { Small and concise, the eyes are round or dotted, and the } \\
\text { beak is mostly open. }\end{array}$ \\
\hline Phoenix body & $\begin{array}{l}\text { Slender, generally more descriptions for the side, head up, } \\
\text { chest, or standing or running. }\end{array}$ \\
\hline Phoenix coronet & $\begin{array}{l}\text { Various styles, with or without crowns, short crowns, long } \\
\text { crowns, rich in shape or large and rich, or simple and } \\
\text { curved. }\end{array}$ \\
\hline Phoenix neck & Slender and long, or curly or elongated. \\
\hline $\begin{array}{l}\text { Phoenix Wing Wind } \\
\text { Blast }\end{array}$ & Large and open, feathery \\
\hline Phoenix leg & \multicolumn{1}{|c|}{ How long and slender, or omitted leg is creeping. } \\
\hline Phoenix foot & Most of them have long feet and sharp claws. \\
\hline
\end{tabular}

China is the earliest textile country in the world, and the textile industry is developed. According to the archaeological findings, the textile industry level of Chu State at that time was sufficient to represent the advanced standards of China's textile industry at that time. Chu is located in the south of China. The humid and rainy soil is especially conducive to the growth of mulberry and other plants, which has become the natural advantage of Chu textile industry. From the Chu tombs in 
Human, Huber, Hen an and other places, we can see many amazing silk fabrics with exquisite weaving technology and complete varieties. The main feature is the exquisite patterns, these patterns are complex, colorful, Phoenix bird pattern is an important theme in Chu textile decoration.

From the Chu tombs found, there are more than ten sites of Chu tombs with jade articles, the earliest of which was the Chu tombs in the middle and late Spring and Autumn Period. "Among the 35 Chu tombs cleaned up here from 1971 to 1973, there are five medium-sized tombs with 40 pieces of jades in the form of small jade bi, jade sulfur, jade gentle, lack of jade, Pearl ornaments, jade pieces and various geometric jade ornaments." Jade decorative patterns are relatively rich, Phoenix bird pattern is not the main theme, compared with lacquer, the number is less, and more jade decorative patterns are auspicious moire, dragon pattern and so on.

\section{Application of Chuffed Decoration in Packaging Design}

Ancient and modern decorations have given Phoenix era patterns, or abstract, or deformation, more widely used, not only reflects the aesthetic significance of vision, but also pays more attention to the connotation of commodities. Under the careful design of many excellent designers, the Phoenix pattern is more colorful.

In today's Chuffed decoration, designers often combine patterns through dots, lines, colors and shapes to arouse consumerist in commodities. In addition to decorative products, packaging patterns are designed to meet the aesthetic needs of consumers. For example, the logo designed for China International Airlines implies that the phoenix flying high, the symbol of image flying smoothly and rapidly, which is closely related to the airlines. The logo has concise and elegant graphics, high profile and full of vitality. It also has the flavor of a new era, reflecting the traditional Chinese culture. The design of the 2008 Beijing Olympic Torch has applied the auspicious implication of thousands of years of Chinese traditional patterns to modern product design, making it an unprecedented representative image.

In modern packaging design, Chufeng decoration stimulates the consumption of goods, so as to achieve the marketing effect and achieve the purpose that enterprises or groups should have.

\section{Innovation of Chuffed Decoration in Modern Packaging Design}

The development of patterns can not blindly follow the old ways. It is necessary to foster maturity in the traditional concepts, abandon the negative and decadent side, retain other reasonable factors and add new contents, so that the inherited patterns can have new contents, functions and structures, and better adapt to the changed environment. Therefore, the integration of Chuffed decoration into modern packaging design requires an innovative method. As shown in the figure below:

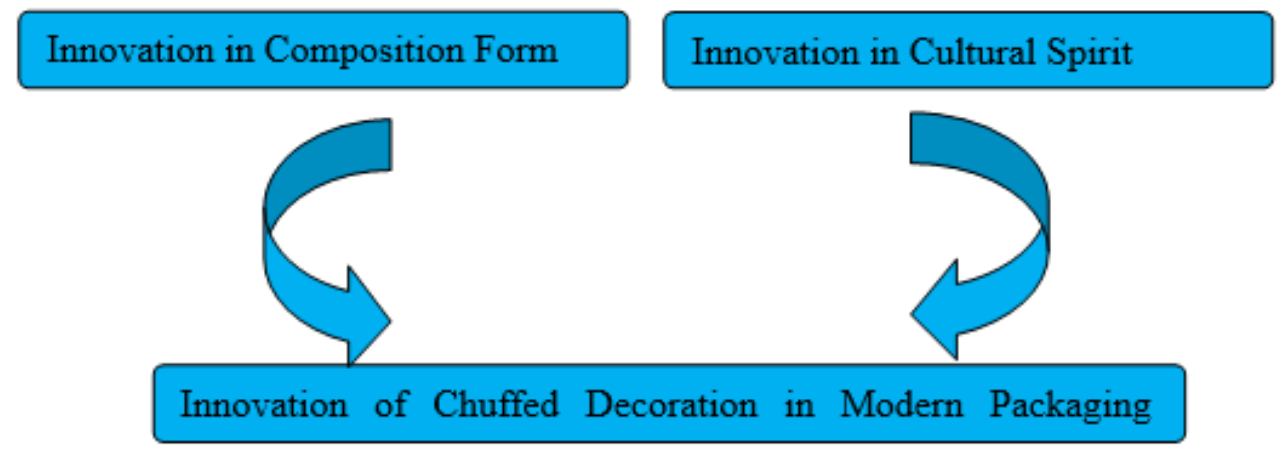

Figure 1 Innovation of Chuffed Decoration in Modern Packaging 


\subsection{Innovation in Composition Form}

Chinese traditional decorative patterns are generally symmetrical and balanced. This graphic structure is often designed to achieve neatness and accuracy, creating a solemn and lively atmosphere. Our modern packaging design can thoroughly break through the traditional form of composition, give full play to subjective initiative, combine modern design principles, create innovative form of composition. For example, the edge and corner concentration type, the symmetrical type with strong density and contrast, the scatter interpolation type, etc., have modern composition style. The design of tobacco and alcohol consumer goods is the most direct visual communication to show local culture. Using regional characteristic culture, we can publicize our long history to the outside world.

\subsection{Innovation in Cultural Spirit}

History is constantly advancing, and human aesthetics and needs are constantly developing. Therefore, the design spirit can not stay at a certain stage, it needs to carry on a kind of innovation in the cultural spirit. Dragon and Phoenix Cup has both traditional and modern style, transparent glass with modern texture, and cup seat is the fusion of Chinese traditional festive color "red and yellow". The yellow metal dragon and Phoenix hover around the base of the cup, matching with the imitation enamel craft. Colorful, diverse materials, has a good visual effect. The image of Phoenix is full of vitality. Only a few lines with the most stylish features are left to outline a beautiful, free and graceful image of Phoenix. This simple wind shape is welded in a more regular geometric shape, with a red agate inlaid on the back, forming a modern shape. Many people will think that the traditional elements are the things that have passed away. It is unavoidable that they are outdated when used in modern design. In fact, tradition is actually the support of creation, and tradition and re-creation are not contradictory. The refinement and application of Chuffed decoration can endow the new spirit of the times.

\section{Conclusion}

In the history of national decorative art, Chufeng pattern is the most representative regional image symbol. The re-creation and inheritance of the mode is not only a positive affirmation of our traditional culture, but also conducive to the protection and research of folk culture. When we pack a national product, we should make a detailed investigation and analysis of all aspects of the product. More importantly, we should have a full understanding of the cultural background of the product. Packaging design should reflect the brand connotation of the product in the first time, so Only by accurately grasping the cultural background of the product, it can convey an accurate artistic conception. In the application of traditional graphics in modern packaging, we should pay attention to the expression of traditional graphics on modern culture. What we need is to recreate the original graphics, not only to show the decorative beauty of the patterns, but also to emphasize the combination of traditional elements and modern visual elements, and to apply them to modern packaging. We should make full use of the origin, development, connotation and symbolic significance of the original pattern as the support point and Enlightenment point, and combine the characteristics of this packaging design.

\section{Acknowledgements}

The Research Project of Humanities and Social Sciences of Hubei Provincial Education Department in 2018 < Design Innovation Research based on Chu Feng pattern in Chu Culture: 
taking Packaging Design as an example > Project achievements, (Project No. 18G060)

\section{References}

[1] Wu Strobing. Symbolic Significance of Vortex Line in Traditional Patterns [J]. Journal of Nanjing Academy of Art, 2016 (3).

[2] Chaos Deng. Design of Dispersion Composition in Geometric Brocade [J]. Auxin: Journal of Shijiazhuang Silk Institute of Technology, 2017 (2).

[3] Institute of Cultural Relics and Archaeology, Huber Province. Tomb of Ch at Giuliani, Yaobang City, Huber [J]. Archaeology, 2013 (7).

[4] Huber Institute of Cultural Relics and Archaeology. Brief Excavation of Ch Tomb in Shijiazhuang, Hangzhou, Huber [J]. Cultural Relics, 2010 (8). 